УДК 618-018.2-007.17

DOI: 10.26435/UC.V0I3(32).331

\author{
В.К. Чайка, А.А. Железная, Н.Н. Лунева
}

ГОО ВПО «Донецкий национальный медицинский университет имени М. Горького», Донецк

\title{
ДИАГНОСТИКА НЕДИФФЕРЕНЦИРОВАННОЙ ДИСПЛАЗИИ СОЕДИНИТЕЛЬНОЙ ТКАНИ У ЖЕНЩИН ДЕТОРОДНОГО ВОЗРАСТА ПО ФЕНОТИПИЧЕСКИМ И ВИСЦЕРАЛЬНЫМ ПРИЗНАКАМ
}

Одним из основных направлений современного акушерства является изучение экстрагенитальных патологий женщин и их влияние на протекание беременности и родов. Именно данные патологии, по мнению многих авторов, могут привести к перинатальным заболеваниям и смертности во время родов. Особое внимание в настоящее время уделяется нарушениям гестации, связанным с недифференцированной дисплазией соединительной ткани $[5,10]$.

Дисплазия соединительной ткани (ДСТ) является генетически детерминированным нарушением развития в эмбриональном и постнатальном периодах. В результате разнообразных мутаций в генах, кодирующих строение коллагена и эластина, формируются дефекты волокнистых структур и основного вещества соединительной ткани с последующим развитием различных морфофункциональных расстройств системного и локального характера. Морфологической основой дисплазии соединительной ткани (ДСТ) служит снижение содержания отдельных видов коллагена или нарушение соотношения между ними, что ведет к снижению прочности соединительной ткани многих органов и систем [4].

В 1990 г. на симпозиуме в Омске, посвященном проблеме врожденной системной дисплазии соединительной ткани, была принята классификация с выделением двух групп указанной патологии. Первая объединяет системные наследственные синдромы, такие, как синдром Марфана, Элерса-Данло, поликистоз почек у взрослых, мукополисахаридоз и другие. В группу недифференцированной дисплазии соединительной ткани (НДСТ) были включены наследственные заболевания соединительной ткани с локомоторно-висцеральными проявлениями [3].

Недифференцированная дисплазия соединительной ткани не наследуется. К ней относят некоторые патологии, чьи фенотипические признаки не соответствуют ни одному из дифференцированных заболеваний [10].

Распространённость НДСТ среди всего населения России по разным источникам колеблется в передах от 20\% до 60\%. Пациентки с этим синдромом чаще, чем здоровые женщины, имеют осложнённое течение беременности и родов $[8,9]$.

Беременность у женщин с НДСТ часто сопровождается угрозой прерывания с формированием субхорионической гематомы в первом триместре, плацентарной недостаточностью, внутриутробной гипоксией плода, гестозами, акушерскими кровотечениями, преждевременными родами и рядом других состояний [8-11].

Многие авторы указывают на малую выявляемость, низкую распознаваемость и отсутствие чётких лабораторных критериев диагностики синдрома НДСТ. Синдром имеет особенность неожиданно реализовываться в крайне неблагоприятных последствиях, особенно в акушерской практике.

По этой причине важной является возможность раннего выявления групп больных с синдромом НДСТ на основе анализа имеющегося набора фенотипических (внешних) признаков, с целью дифференцированного подхода к тактике ведения беременности у таких пациенток [5-7].

Внешние признаки соединительнотканной дисплазии представлены конституциональными особенностями, аномалиями развития костей скелета, кожи и др. Пациентки с дисплазией соединительной ткани имеют астеническую конституцию: высокий рост, узкие плечи, дефицит массы тела. Нарушения развития осевого скелета могут быть представлены сколиозом, кифозом, воронкообразной или килевидной деформациями грудной клетки, ювенильным остеохондрозом [10].

(c) В.К. Чайка, А.А. Железная, Н.Н. Лунева, 2019 (c) Университетская Клиника, 2019 
Краниоцефальные аномалии соединительнотканной дисплазии нередко проявляются долихоцефалией, нарушениями прикуса, аномалиями зубов, готическим небом, несращением верхней губы и нёба.

Патология костно-суставной системы характеризуется О-образной или Х-образной деформацией конечностей, синдактилией, арахнодактилией, гипермобильностью суставов, плоскостопием, склонностью к привычным вывихам и подвывихам, переломам костей.

Со стороны кожных покровов отмечается повышенная растяжимость (гиперэластичность) или, напротив, хрупкость и сухость кожи. Нередко на коже без видимых причин возникают стрии, пигментные пятна либо очаги депигментации, сосудистые дефекты (телеангиэктазии, гемангиомы) [10].

Слабость мышечной системы при соединительнотканной дисплазии обусловливает склонность к опущению и выпадению внутренних органов, грыжам, мышечной кривошее [3, 6, 8].

Из других внешних признаков соединительнотканной дисплазии могут встречаться такие микроаномалии, как гипо- или гипертелоризм, лопоухость, асимметрия ушей, низкая линия роста волос на лбу и шее и др. [10].

Висцеральные поражения протекают с заинтересованностью ЦНС и вегетативной нервной системы, различных внутренних органов. Неврологические нарушения, сопутствующие соединительнотканной дисплазии, характеризуются вегетососудистой дистонией, астенией, энурезом, хронической мигренью, нарушением речи, высокой тревожностью и эмоциональной неустойчивостью $[3,10]$.

Синдром соединительнотканной дисплазии сердца может включать в себя пролапс митрального клапана, открытое овальное окно, гипоплазию аорты и легочного ствола, удлинение и избыточную подвижность хорд, аневризмы коронарных артерий или межпредсердной перегородки $[1,11]$.

Следствием слабости стенок венозных сосудов служит развитие варикозного расширения вен нижних конечностей и малого таза, геморрой. Пациенты с соединительнотканной дисплазией имеют склонность к возникновению артериальной гипотензии, аритмий, атриовентрикулярных и внутрижелудочковых блокад, кардиалгий, внезапной смерти [8-10].

Кардиальным проявлениям нередко сопутствует бронхолегочный синдром, характеризующийся наличием кистозной гипоплазии легких, бронхоэктазов, буллезной эмфиземы, повторных спонтанных пневмотораксов [11].

Характерно поражение ЖКТ в виде опуще- ния внутренних органов, дивертикулов пищевода, гастроэзофагеального рефлюкса, грыжи пищеводного отверстия диафрагмы [3].

Типичными проявлениями патологии органа зрения при соединительнотканной дисплазии служат близорукость, астигматизм, дальнозоркость, нистагм, косоглазие, вывих и подвывих хрусталика [10].

Со стороны мочевыделительной системы может отмечаться нефроптоз, недержание мочи, почечные аномалии (гипоплазия, удвоение, подковообразная почка) и пр. [4, 5, 8].

Репродуктивные нарушения, ассоциированные с соединительнотканной дисплазией, у женщин могут быть представлены опущением матки и влагалища, метро- и меноррагией, самопроизвольными абортами, послеродовыми кровотечениями $[4,7]$.

Лица, имеющие признаки соединительнотканной дисплазии, склонны к частым ОРВИ, аллергическим реакциям, геморрагическому синдрому [9].

Заболевания из группы соединительнотканных дисплазий не всегда диагностируются правильно и своевременно. Часто больные с теми или иными признаками дисплазии наблюдаются у врачей разных специальностей: травматологов, неврологов, кардиологов, пульмонологов, нефрологов, гастроэнтерологов, офтальмологов и др. $[9,10]$.

Распознавание недифференцированных форм соединительнотканной дисплазии усложняется отсутствием единых алгоритмов диагностики. Наибольшей диагностической значимостью обладает выявление совокупности фенотипических и висцеральных признаков [2].

С целью обнаружения последних широко применяются ультразвуковые (ЭхоКГ, УЗИ почек, УЗИ органов брюшной полости), эндоскопические (ФГДС), электрофизиологические (ЭКГ, ЭЭГ), рентгенологические (рентгенография легких, суставов, позвоночника и др.) методы [9].

Выявление характерных полиорганных нарушений, главным образом со стороны опорнодвигательной, нервной и сердечно-сосудистой систем, с высокой степенью вероятности свидетельствует о наличии соединительнотканной дисплазии [7].

Ряд авторов полагает, что тяжесть НДСТ определяется клинической значимостью и числом фенотипических проявлений или «фенов». Для диагностики наличия НДСТ у беременных и, соответственно, прогнозирования возможных исходов беременности у данной пациентки представляет наибольший интерес определенный набор «фенов» ДСТ. Внешними проявлениями ДСТ, как правило, служат стигмы дизэмбри- 
огенеза. Диагностическая значимость и клиническая оценка стигм дизэмбриогенеза различны [2].

Существует несколько подходов к трактовке веса отдельных стигм и их необходимого количества для верификации диагноза ДСТ. Фенотипические признаки могут быть расценены как клинически значимый синдром ДСТ. Чем меньше этих признаков и чем слабее они выражены, тем больше оснований считать их вариантом нормального развития соединительной ткани. [11]. Для диагностики синдрома ДСТ по В.А. Таболину, Н.П. Шабалову [2] критическим количеством признаков является наличие 6 и более стигм дизэмбриогенеза.

Смольнова Т.Ю. и соавт. полагают, что критерии диагноза ДСТ не являются постоянными на протяжении жизни индивида, и при постановке диагноза ДСТ с помощью фенотипических маркеров необходимо учитывать возраст [6].

Практически все авторы свидетельствуют о достаточно тесной связи между числом внешних фенотипических признаков ДСТ и частотой выявления ДСТ внутренних органов. При выявлении 3-х и более стигм даже при отсутствии жалоб показано более тщательное соматическое обследование для диагностики патологии внутренних органов $[1,6]$.

Никифорова Н.В. [9] использует 2 группы признаков (фенотипические и висцеральные) для диагностики НДСТ, и при наличии 5 и более признаков у беременных выставляется диагноз НДСТ. Однако при этом не учитываются диагностическая информативность и значимость признаков.

В связи с этим критическое число признаков для диагностики НДСТ по-прежнему остается несогласованным.

Керимкулова В.А. [2] предлагает прогнозировать наличие НДСТ у беременных на основе 16 высокоинформативных признаков 1 и 2 ранга, включающих фенотипические и висцеральные маркеры дисплазии соединительной ткани. Наличие 2 и более признаков свидетельствует о недифференцированной дисплазии соединительной ткани. Диагноз НДСТ ставится, если у пациентки найдено не менее 2 из 16 высокоинформативных фенов.

Эффект предлагаемого способа заключается в том, что он позволяет провести своевременную диагностику НДСТ у беременных и выявить группы риска акушерской патологии, а также прогнозировать и профилактировать осложнения беременности на этапах предгравидарной подготовки, в течение всей беременности, начиная с ранних сроков гестации, в родах и раннем послеродовом периоде. Данные мероприятия позволяют значительно снизить частоту перинатальной заболеваемости и смертности. Способ отличается высокой чувствительностью (94\%), специфичностью (100\%), простотой и доступностью применения, т.к. для диагностики врачом будет использоваться минимально возможное число высокоинформативных признаков 1 и 2 рангов (1-16).

Однако такой подход не позволяет оценить степень выраженности НДСТ. Смольнова Т.Ю. предлагает разделить все признаки НДСТ на три группы: малые признаки (оцениваются 1 баллом), большие признаки (2 балла), тяжелые проявления и состояния (3 балла). Суммой набранных баллов характеризуется степень выраженности ДСТ. Маловыраженная ДСТ (легкая степень тяжести) - до 9 баллов, умеренно выраженная (средняя степень тяжести) - 10-16 баллов, выраженная (тяжелая степень) - более 17 баллов [8].

Методы диагностики НДСТ дополняются исследованиями биохимических показателей крови, системы гемостаза, иммунного статуса, проводится биопсия кожи. В качестве метода скрининг-диагностики соединительнотканной дисплазии предложено проводить исследование папиллярного рисунка кожи для матери и плода при недифференцированной дисплазии соединительной ткани передней брюшной стенки: выявление неоформленного типа папиллярного рисунка служит маркером диспластических нарушений. Семьям, где имеются случаи соединительнотканной дисплазии, рекомендуется пройти медико-генетическое консультирование [3].

Прогноз соединительнотканной дисплазии во многом зависит от степени выраженности диспластических нарушений. У пациентов с изолированными формами качество жизни может не нарушаться. У больных с полисистемным поражением повышен риск ранней и тяжелой инвалидизации, преждевременной смерти, причинами которой могут выступать фибрилляция желудочков, ТЭЛА, разрыв аневризмы аорты, геморрагический инсульт, тяжелые внутренние кровотечения [10]. 


\section{В.К. Чайка, А.А. Железная, Н.Н. Лунева}

ГОО ВПО «Донецкий национальный медицинский университет имени М. Горького», Донецк

\section{ДИАГНОСТИКА НЕДИФФЕРЕНЦИРОВАННОЙ ДИСПЛАЗИИ СОЕДИНИТЕЛЬНОЙ ТКАНИ У ЖЕНЩИН ДЕТОРОДНОГО ВОЗРАСТА ПО ФЕНОТИПИЧЕСКИМ И ВИСЦЕРАЛЬНЫМ ПРИЗНАКАМ}

Дисплазия соединительной ткани является генетически детерминированным нарушением развития в эмбриональном и постнатальном периодах. Морфологической основой дисплазии соединительной ткани служит снижение содержания отдельных видов коллагена или нарушение соотношения между ними, что ведет к снижению прочности соединительной ткани многих органов и систем. Различают наследственные синдромы и недифференцированную дисплазию соединительной ткани.

Беременность у женщин с недифференцированной дисплазией соединительной ткани часто сопровождается угрозой прерывания с формированием субхорионической гематомы в первом триместре, плацентарной недостаточностью, внутриутробной гипоксией плода, гестозами, акушерскими кровоте- чениями, преждевременными родами и рядом других состояний.

Диагностика недифференцированной дисплазии соединительной ткани осложняется разнообразными проявлениями патологического синдрома и отсутствием единых критериев диагностики. Цель обзора - осветить основные способы ранней диагностики недифференцированной дисплазии соединительной ткани и степени выраженности патологических нарушений синдрома у женщин репродуктивного возраста.

Ключевые слова: недифференцированная дисплазия соединительной ткани, способы диагностики, репродуктивный возраст, фенотипические и висцеральные признаки.

\section{V.K. Chayka, A.A. Zheleznaya, N.N. Luneva}

SEI HPE «M. Gorky Donetsk National Medical University», Donetsk

\section{DIAGNOSTICS OF UNDIFFERENTIATED CONNECTIVE TISSUE DYSPLASIA IN WOMEN OF REPRODUCTIVE AGE BY PHENOTYPIC AND VISCERAL SIGNS}

Connective tissue dysplasia is a genetically determined developmental disorder in the embryonic and postnatal periods. The morphological basis of connective tissue dysplasia is a decrease in the content of certain types of collagen or a violation of the ratio between them. This is the reason for reducing the strength of the connective tissue of many organs and systems. There are hereditary syndromes and undifferentiated connective tissue dysplasia.

Pregnancy in women with undifferentiated connective tissue dysplasia is often accompanied by the threat of interruption with the formation of subchorionic hematoma in the first trimester, placental insufficiency, fetal hypoxia, gestosis, obstetric hemorrhage, premature birth and other conditions.

Diagnosis of undifferentiated connective tissue dysplasia is complicated by various manifestations of the pathological syndrome and the lack of uniform diagnostic criteria. The purpose of the review is to present the main methods of early diagnosis of undifferentiated connective tissue dysplasia and the severity of pathological disorders of the syndrome in women of reproductive age.

Key words: undifferentiated connective tissue dysplasia, diagnostic methods, reproductive age, phenotypic and visceral signs.

\section{ЛИТЕРАТУРА}

1.Земцовский Э.В. Соединительнотканные дисплазии сердца: монография. СПб.: ТОО «Политекс-НордВест»; 2000. 115.

2. Керимкулова В.А., Никифорова Н. В., Громова О. А., Торшин И.Ю. Патент РФ № 2013118898/14А; 2013.

3. Козинова О.А. Недифференцированная дисплазия соединительной ткани и беременность: автореф. дис. ... доктора мед. наук. Москва; 2008. 38.

4. Комиссарова Л.М., Карачаева А.Н., Кесова М.И. Течение беременности и родов при дисплазии соединительной ткани. Акушерство и гинекология. 2012; 3: 4-8.

5. Масленников А.В. Особенности течения беременности и родов у женщин с недифференцированной дисплазией соединительной ткани: автореф. дис....канд. мед. наук. Уфа; 2014. 22.

6. Смольнова Т.Ю., Адамян Л.В., Ляшко Е.С. Синдром дисплазии соединительной ткани в акушерстве и гинекологии. Современные технологии в диагностике и лече-

\section{REFERENCES}

1. Zemtsovskiy E.V. Soedinitelnotkannyie displazii serdtsa: monografiya [Connecting tissue heart dysplasia: monograph]. SPb.: TOO «Politeks-Nord-Vest»; 2000. 115 (in Russian).

2. Kerimkulova V.A., Nikiforova N. V., Gromova O. A., Torshin I.Yu. Patent RF \# 2013118898/14A; 2013 (in Russian).

3. Kozinova O.A. Nedifferentsirovannaya displaziya soedinitelnoy tkani i beremennost: avtoref. dis.... doktora med. nauk [Undifferentiated dysplasia of connecting fabric and pregnancy: Doc. med. sci. diss. abs.]. Moskva; 2008. 38 (in Russian).

4. Komissarova L.M., Karachaeva A.N., Kesova M.I. Techenie beremennosti i rodov pri displazii soedinitelnoy tkani [The course of pregnancy and childbirth at a dysplasia of connecting fabric]. Akusherstvo i ginekologiya. 2012; 3: 4-8 (in Russian).

5. Maslennikov A.V. Osobennosti techeniya beremennosti i rodov $\mathrm{u}$ zhenschin s nedifferentsirovannoy displaziey soe- 
нии гинекологических заболеваний / под ред. Кулакова В.И., Адамян Л.В. Москва; 2005: 257.

7. Смольнова Т.Ю., Адамян Л.В. Критерии постановки диагноза дисплазии соединительной ткани у женщин. Актуальные вопросы внутренней патологии. Дисплазия соединительной ткани: материалы Первой всероссийской научно-практической конференции. 29 - 30 июня 2005. Омск; 2005: 156.

8. Смольнова Т.Ю. Клинико-патогенетические аспекты опущения и выпадения внутренних половых органов и патологии структур тазового комплекса у женщин при дисплазии соединительной ткани. Тактика ведения: автореф. дис. ... доктора мед. наук. М.; 2009. 54.

9. Никифорова Н.В., Керимкулова Н.В., Сонин Д.О., Пахомова К.В., Сонина Н.П. Распространенность недифференцированной дисплазии соединительной ткани в популяции беременных и ее влияние на гестационный процесс. Вестник Ивановской медицинской академии. 2011;16 (2): 81-82.

10. Фадеева Т. С. Дисплазия соединительной ткани: новые горизонты проблемы: монография. Чебоксары: ИД «Среда»; 2018. 76.

11. Яковлев В.М., Нечаева Г.И. Кардиореспираторные синдромы при дисплазии соединительной ткани. Омск; 1994. 217. dinitelnoy tkani: avtoref. dis....kand. med. nauk [Features of a course of pregnancy and childbirth at women with an undifferentiated dysplasia of connecting fabric: Cand. med. sci. diss. abs.]. Ufa; 2014. 22 (in Russian).

6. Smolnova T.Yu., Adamyan L.V., Lyashko E.S. Sindrom displazii soedinitelnoy tkani v akusherstve i ginekologii [Syndrome of a dysplasia of connecting fabric in obstetrics and gynecology]. Sovremennyie tehnologii v diagnostike i lechenii ginekologicheskih zabolevaniy / pod red. Kulakova V.I., Adamyan L.V. Moskva; 2005: 257 (in Russian).

7. Smolnova T.Yu., Adamyan L.V. Kriterii postanovki diagnoza displazii soedinitelnoy tkani $u$ zhenschin. Aktualnyie voprosyi vnutrenney patologii [Criteria of diagnosis of a dysplasia of connecting fabric at women]. Displaziya soedinitelnoy tkani : materialyi Pervoy vserossiyskoy nauchno-prakticheskoy konferentsii. 29 - 30 iyunya 2005. Omsk; 2005: 156 (in Russian).

8. Smolnova T.Yu. Kliniko-patogeneticheskie aspektyi opuscheniya i vyipadeniya vnutrennih polovyih organov i patologii struktur tazovogo kompleksa u zhenschin pri displazii soedinitelnoy tkani. Taktika vedeniya: avtoref. dis. ... doktora med. nauk [Clinical and pathogenetic aspects of omission and loss of internal genitals and pathology of structures of a pelvic complex at women at a dysplasia of connecting fabric. Maintaining tactics: Doc. med. sci. diss. abs.]. M.; 2009. 54 (in Russian).

9. Nikiforova N.V., Kerimkulova N.V., Sonin D.O., Pahomova K.V., Sonina N.P. Rasprostranennost nedifferentsirovannoy displazii soedinitelnoy tkani $\mathrm{v}$ populyatsii beremennyih i ee vliyanie na gestatsionnyiy protsess [Prevalence of an undifferentiated dysplasia of connecting fabric in populations of pregnant women and its influence on gestational process]. Vestnik Ivanovskoy meditsinskoy akademii. 2011;16 (2): 81-82 (in Russian).

10. Fadeeva T. S. Displaziya soedinitelnoy tkani: novyie gorizontyi problemyi: monografiya [Dysplasia of connecting fabric: new horizons of a problem: monograph]. Cheboksaryi: ID «Sreda»; 2018. 76 (in Russian).

11. Yakovlev V.M., Nechaeva G.I. Kardiorespiratornyie sindromyi pri displazii soedinitelnoy tkani [Cardiorespiratory syndromes at a dysplasia of connecting fabric]. Omsk; 1994. 217 (in Russian). 